\title{
Smoking, exposure to crocidolite, and the incidence of lung cancer and asbestosis
}

\author{
Nicholas H de Klerk, A William Musk, Bruce K Armstrong, Michael S T Hobbs
}

\begin{abstract}
In 1979 all former workers from the Wittenoom asbestos industry who could be traced to an address were sent a questionnaire to determine smoking history. Occupational exposure to crocidolite was known from employment records. Of 2928 questionnaires sent, satisfactory replies were received from 2400 men and 149 women. Eighty per cent of these had smoked at some time and $50 \%$ were still smoking. Since that time 40 cases of lung cancer and 66 cases of compensatable asbestosis have occurred in this cohort. The incidence of both lung cancer and asbestosis was greatest in those subjects with the highest levels of exposure to crocidolite and in ex-smokers. Statistical modelling of the joint effects of these exposures on the incidence of each disease indicated that crocidolite exposure multiplied the rates of lung cancer due to smoking and that smoking had no measurable effect on the rates of asbestosis. There was also some evidence that the incidence rate of lung cancer is falling with time.
\end{abstract}

Crocidolite was mined at Wittenoom in Western Australia from 1937 until 1966. From 1943 until 1966 the principal leases were mined by a single company, Australian Blue Asbestos (ABA), which employed over 6000 people, mostly for short periods. The employment records of the company have formed the basis of a continuing cohort mortality study of the workforce. ${ }^{12}$ The workforce has been shown to have raised incidence and mortality from asbestosis, lung cancer, and malignant mesothelioma. The increases

NH and MRC Unit of Epidemiology and Preventive Medicine

$\mathrm{N} \mathrm{H}$ de Klerk

Unit of Clinical Epidemiology, Department of Medicine, University of Western Australia

M S T Hobbs

Department of Respiratory Medicine, Sir Charles Gairdner Hospital, Perth, Western Australia A W Musk

Health Department of Western Australia

B K Armstrong in incidence of these three known asbestos related diseases have shown clear associations with both level and duration of exposure to asbestos. ${ }^{123}$ Higher than expected mortality from alcohol related diseases and other smoking related diseases has also been recorded as well as excesss mortality from tuberculosis, attributed to the migrant state of the workers. ${ }^{1}$

Cigarette smoking and exposure to one or other form of asbestos are both known to cause lung cancer and most evidence suggests that their effects are multiplicative in its production. ${ }^{45}$ This is to be expected because smoking and asbestos probably act at different stages in the process of carcinogenesis. ${ }^{6}$ The combined effects of smoking and exposure to crocidolite alone on risk of lung cancer have not previously been shown prospectively except by Baker $^{7}$ in an earlier study on the Wittenoom workers. That study used only rough groupings of worksite to estimate exposure to crocidolite and was restricted to cases of lung cancer arising in Western Australia.

It has long been known that diffuse interstitial pulmonary fibrosis can be caused by asbestos and that the occurrence of this disease and its severity have declined consistently since the introduction of dust suppression methods throughout industries in which asbestos has been used. ${ }^{8}$ Although asbestosis does not occur in the unexposed general population, radiographic abnormalities consistent with asbestosis have been found in $10 \%$ or more of members of the families of amosite factory workers and shipyard workers $^{910}$ and $5 \%$ to $30 \%$ of occupational cohorts mostly exposed to mixtures of types of asbestos. ${ }^{11}{ }^{12}$ Definite exposure reponse relations between both level and duration of exposure to asbestos and presence of definite radiographic abnormalities have been shown by many authors, ${ }^{11-14}$ and similar relations exist for mortality from asbestosis. Many, but not all, studies ${ }^{15}$ have also shown that smoking increases the prevalence of abnormal findings on $x$ ray films in populations of asbestos workers, ${ }^{16-20}$ that smoking may increase the rate of progression of parenchymal asbestosis, ${ }^{1921}$ and that prevalence of abnormal radiographs is also related to age..$^{11^{1720}}$ One longitudinal study has also shown independent effects of cumulative exposure, smoking habit, and age on the incidence of abnormality. ${ }^{22}$

The Wittenoom cohort provides a unique opportunity to study these exposure response relations for subjects exposed almost exclusively to crocidolite. 
Previous studies on the Wittenoom cohort have shown positive effects of cumulative exposure on the prevalence ${ }^{23}$ and the severity of radiographic asbestosis, ${ }^{24}$ on mortality from asbestosis, ${ }^{13}$ and on the rate of progression of established asbestosis. ${ }^{25}$

The aim of this study was to examine the separate and combined effects of smoking and exposure to crocidolite on the incidence of lung cancer and asbestosis in workers exposed only to crocidolite.

\section{Subjects}

There were 6500 known employees of the Australian Blue Asbestos Company between 1943 and 1966. A total of 2928 of these workers were traced in 1979 and were sent a questionnaire on smoking and other occupational exposures. Two thousand four hundred men replied. These constitute the cohort for this study. Follow up of this cohort has been maintained since that date.

\section{Methods}

Methods of follow up, ascertainment of vital state, and estimation of levels of exposure to crocidolite have been described in full previously. ${ }^{12}$ Briefly, demographic and basic exposure data were obtained from employment records supplemented, when incomplete, by records of the Perth chest clinic, which performed compulsory pre-employment and subsequent periodic examinations by chest $x$ ray film of all employees, and by records of the Western Australian Mineworkers Relief Fund, a compulsory benevolent fund to which the company paid monthly subscriptions deducted from each employee.

Ascertainment of vital state in this cohort of questionnaire responders has been chiefly carried out by periodic mailing since 1979 . Where necessary this information has been supplemented by access to death registries in all States of Australia from 1 January 1981 to 31 December 1986, all State and Commonwealth electoral rolls current in 1986 or later, and all Australian telephone directories current in 1986 or later.

A survey of airborne respirable fibres of crocidolite greater than $5 \mu \mathrm{m}$ in length was carried out at various work sites at Wittenoom in $1966 .{ }^{26}$ These measurements were used to obtain estimates of fibre concentrations for all 87 job categories in the various worksites. A subjective ranking of the degree of dustiness of these jobs, both before and after September 1957, when a less dusty mill commenced operation, had been provided by an ex-superintendent of operations at Wittenoom and verified by the industrial hygienist who conducted the 1966 survey. ${ }^{1}$ The subjective ranking of each job was combined with the results of the 1966 survey of fibre concentrations to provide an estimate of dust exposure for every job at
Wittenoom. The scale was used to estimate fibre concentrations in earlier periods and in jobs not included in the survey.

This study was designed as a case-control study within the cohort of 2400 people. ${ }^{27}$ The incident cases of asbestosis and lung cancer were identified by a date of diagnosis after the date of returning the questionnaire up to December 1986. The date of diagnosis of asbestosis for each subject was established through the records of the Pneumoconiosis Medical Panel of Western Australia, which handles workers compensation claims for dust diseases in this State and from death certificates obtained from the Registrars General throughout Australia. The date of diagnosis of lung cancer for each subject was established through the Pneumoconiosis Medical Panel and death certificates as well as through all cancer registries in Australia. Each case of asbestosis and lung cancer was matched to all subjects from the cohort who were not known to have developed asbestosis, lung cancer, or malignant mesothelioma by the year of diagnosis of the case, who were the same age (exact year), and who were known to be alive in the year of the case's diagnosis of asbestosis or lung cancer. Thus subjects could be controls for more than one case and some cases could be controls for other earlier cases. Variables compared between cases and controls were smoking state, average intensity of exposure to crocidolite (fibres (f)/ml), duration of crocidolite exposure (days), time since first exposure (years), year of birth, year of starting work (before 1950, 1950-6, after 1956), cumulative exposure to crocidolite and work site (mill only, mill and elsewhere (including mine and unknown), mine only, mine and elsewhere (not including mill), neither mine nor mill, and unknown.

Smoking habit was categorised as that given on the questionnaire and was assumed not to change throughout the study. For ex-smokers it was therefore assumed that the time since they had last smoked was the time between giving up and the time of diagnosis of their disease or that of the matched case.

\section{Statistical methods}

The frequencies of the variables of interest in the matched sets of cases and controls were compared using conditional logistic regression analysis to estimate odds ratios by use of the computer program EGRET ${ }^{28}$ For tabular presentations, because cases were matched to sets of controls of varying sizes, variables were averaged across each control set before taking the overall average.

The odds ratio was taken to approximate the relative risk or rate ratio. Interaction odds ratios were also estimated to examine the goodness of fit of the multiplicative model to the data. A poor fit would be 
suggested by interaction odds ratios that were different from one; terms less than one showing that the relative effect of asbestos was less in smokers than non-smokers (or conversely, that the relative effect of smoking was less in those exposed to asbestos than those unexposed) and that the combined effects would be likely to be additive, with terms greater than one implying a combined effect that would be more than multiplicative, as for example in initial analyses of American insulation workers where no lung cancers occurred in non-smokers. ${ }^{29}$

Other workers have generally expressed the relative risks of lung cancer for asbestos workers in terms of their cumulative exposure (the product of duration of exposure and level of exposure summed over all different jobs, sites, etc). ${ }^{30} 3132$ Although this may be an inappropriate measure from the theoretical point of view $^{33}$ and is certainly inappropriate for mesothelioma, ${ }^{38}$ analogous to the inappropriate use of pack-years of cigarette-smoking when assessing risk from tobacco,$^{34}$ it has received widespread use and often appears to fit available data better than the separate terms. Accordingly, in this study, different measures of exposure were used in alternative models and the relative goodness of fit of these non-hierarchical models was assessed using differences in the residual deviance. ${ }^{35}$

\section{Results}

LUNG CANCER

There were 40 cases of lung cancer and 1799 matched controls. The mean duration of exposure to crocidolite for cases of lung cancer was nearly twice that of the control subjects (table 1). The intensity of exposure to crocidolite and time since exposure did not appear to be different between the cases and controls. The proportion of subjects who had never smoked or who had stopped smoking more than 10 years before replying to the questionnaire was lower in the control subjects than in those with cancer, whereas the proportion of subjects who had recently stopped smoking or who continued to smoke was greater in the lung cancer cases than in the controls.

The relative risk associated with exposure to asbestos was slightly greater in smokers than in nonsmokers (table 2). The larger effect of exposure to asbestos in smokers was not significantly different from previous findings of a likely multiplicative model, for which the relative effect of asbestos would be expected to be one.

When all the variables listed in table 1 were included in the same model the relative risk of lung cancer in the current smokers was roughly five (table 3). This was slightly greater in heavier smokers. It rose to 13.9 in subjects who had stopped smoking within six years of the date of diagnosis of the index case and then fell to $7 \cdot 2$ in those who had stopped
Table 1 Lung cancer: asbestos and cigarette smoke exposure variables

\begin{tabular}{lcc}
\hline & $\begin{array}{l}\text { Cases } \\
(n=40)\end{array}$ & $\begin{array}{l}\text { Controls } \\
(n=1799)\end{array}$ \\
\hline Crocidolite exposure state: & 726 & 450 \\
Mean duration (days) & 28 & 24 \\
Mean intensity (f/ml) & 49 & 26 \\
Mean cumulative (f/ml-years) & 25 & 28 \\
Mean time since first exposed (y) & 25 & \\
Smoking state (\%): & & \\
Never smoked & 7.5 & 25 \\
Ex $>10$ y & 7.5 & 20 \\
Ex 6-10 y & 15 & 8 \\
Ex <6 y & 12.5 & 4 \\
Current <20/day & 25 & 19 \\
Current $\geqslant 20 /$ day & 32.5 & 24 \\
\hline
\end{tabular}

${ }^{\star}$ Mean of the mean of each set of controls.

Table 2 Lung cancer: relative effects of smoking and asbestos exposure

\begin{tabular}{|c|c|c|c|c|}
\hline & \multicolumn{4}{|c|}{ Asbestos exposure ${ }^{\star}$} \\
\hline & \multicolumn{2}{|c|}{ Non-smokers $\dagger$} & \multicolumn{2}{|c|}{ Smokers } \\
\hline & High & Low & High & Low \\
\hline $\begin{array}{l}\text { Cases } \\
\text { Controls }\end{array}$ & $\begin{array}{r}4 \\
357\end{array}$ & $\begin{array}{r}2 \\
399\end{array}$ & $\begin{array}{r}25 \\
521\end{array}$ & $\begin{array}{r}9 \\
522\end{array}$ \\
\hline $\begin{array}{l}\text { Relative risk } \\
\text { Matched analysis ( } 95 \% \mathrm{CI} \text { ) } \\
\text { Relative asbestos effect (NS:S) }\end{array}$ & \multicolumn{4}{|c|}{$\begin{array}{l}1.90(0.62-5.85) 2.62(1 \cdot 18-5.79) \\
0.73(95 \% \mathrm{CI}, 0 \cdot 11-5.80) \\
(p=0.74)\end{array}$} \\
\hline
\end{tabular}

^Low exposure here is less than $10 \mathrm{f} / \mathrm{ml}$-years.

$\dagger$ Non-smokers include ex-smokers of longer than 10 years.

Table 3 Lung cancer: relative risks for combined cigarette smoking and asbestos exposure, all variables included together in a single model

\begin{tabular}{lc}
\hline & $\begin{array}{l}\text { Relative risk } \\
(95 \% \mathrm{CI})\end{array}$ \\
\hline Asbestos exposure: & $1 \cdot 40(1 \cdot 12-1 \cdot 75)$ \\
$\quad$ Total cumulative (per $\log _{e}(\mathrm{f} / \mathrm{ml}$-years $\left.)\right)$ & $0 \cdot 48(0 \cdot 24-0 \cdot 98)$ \\
Time since first exposed $(>25 \mathrm{y})$ & \\
Smoking state: & $1 \cdot 0$ \\
$\quad$ Never & $1 \cdot 30(0 \cdot 25-6.90)$ \\
Ex $>10 \mathrm{y}$ & $7 \cdot 21(1 \cdot 63-31 \cdot 9)$ \\
Ex $6-10 \mathrm{y}$ & $13.9(2 \cdot 84-67 \cdot 7)$ \\
Ex $<6 \mathrm{y}$ & $4 \cdot 49(1 \cdot 17-17 \cdot 2)$ \\
Current $<20 /$ day & $5 \cdot 76(1 \cdot 51-22 \cdot 0)$ \\
Current $\geqslant 20 /$ day & \\
\hline
\end{tabular}

smoking 6-10 years previously. It then fell to 1.3 with more than 10 years since stopping smoking. Adjustment of the relative risks for both smoking and exposure to crocidolite made no difference to either set of relative risks indicating little or no confounding. These relative risks were all significantly greater than one, except for ex-smokers of longer than 10 years duration. There was no significant interaction 
term between smoking and exposure to crocidolite ( $p>0.4$ in all cases) showing that the multiplicative model fitted the data reasonably well.

The relative risk of lung cancer was significantly related to the duration of crocidolite exposure and also to cumulative exposure to crocidolite. When added to a model including duration of exposure, the effect of intensity of exposure, although small, was almost significant $(p=0 \cdot 10)$. Relative risks were $1 \cdot 18$ (95\% confidence interval $(95 \% \mathrm{CI}) 1.04-1.33)$ per year of exposure and $1.08(95 \% \mathrm{CI} 0.97-1.20)$ per 10 $\mathrm{f} / \mathrm{ml}$. An apparently better fit to the data was, however, obtained using log (cumulative exposure) in place of the separate terms for intensity and duration of exposure with the residual deviance lower by 3.3 with one less parameter estimated.

The only other significant variable was a term for years since first exposed. The best fit for the data here, indicated by examining the effects of the variable after categorisation, was a single term with a lower relative risk of $0 \cdot 48(95 \% \mathrm{CI} 0 \cdot 24-0.98)$ for those first exposed more than 25 years ago (table 3 ).

\section{ASBESTOSIS}

The mean duration of exposure to crocidolite was nearly three times as high in the 66 subjects with asbestosis as in the 2647 control subjects (table 4). Intensity of exposure was also higher among cases than controls, as was cumulative exposure. No difference in smoking habits between the two groups was found.

The best fitting model for exposure to asbestos (table 5) included a quadratic term in either duration of exposure or cumulative exposure. As with lung cancer, the model with cumulative exposure was a better fit (a reduction of 2.5 in the residual deviance with one less term estimated).

The only other significant effect was that for work site $(p=0.005)$ with the highest rates associated with work in the mine proper. Smoking had no

Table 4 Asbestosis: asbestos and cigarette smoke exposure variables

\begin{tabular}{lcc}
\hline & $\begin{array}{l}\text { Cases } \\
(n=66)\end{array}$ & $\begin{array}{l}\text { Controls } \\
(n=2647)\end{array}$ \\
\hline Crocidolite exposure state: & 1000 & 394 \\
$\quad$ Mean duration (days) & 35 & 25 \\
Mean intensity (f/ml) & 71 & 23 \\
Mean cumulative (f/ml-years) & 25 & 26 \\
Mean time since first exposed (y) & & \\
Smoking status (\%): & 21 & 21 \\
Never smoked & 21 & 19 \\
Ex $>10$ y & 9 & 8 \\
Ex 6-10y & 11 & 6 \\
Ex <6 y & 15 & 20 \\
Current <20/day & 24 & 26 \\
Current $\geqslant 20 /$ day & & \\
\hline
\end{tabular}

^Mean of the mean of each set of controls.
Table 5 Asbestosis: relative risk for combined cigarette smoking and asbestos exposure, all variables included together in a single model

\begin{tabular}{|c|c|}
\hline & $\begin{array}{l}\text { Relative risk } \\
\text { (95\% CI })\end{array}$ \\
\hline $\begin{array}{l}\text { Asbestos exposure: } \\
\text { Total cumulative (per }(\mathrm{f} / \mathrm{ml} \text {-years })) \\
\text { Total cumulative }^{2}\left(\operatorname{per}\left(\mathrm{f} / \mathrm{ml}^{2} \text {-years }\right)^{2}\right)\end{array}$ & $\begin{array}{l}1.033(1.021-1.045) \\
0.999(0.999-1.000)\end{array}$ \\
\hline $\begin{array}{l}\text { Site of work: } \\
\text { Neither mine nor mill } \\
\text { Mill only } \\
\text { Mine only } \\
\text { Mill and elsewhere } \\
\text { Mine and elsewhere } \\
\text { Unknown }\end{array}$ & $\begin{array}{l}1 \cdot 0 \\
2 \cdot 71(1 \cdot 13-6 \cdot 20) \\
6 \cdot 99(3 \cdot 43-14 \cdot 23) \\
6 \cdot 45(2 \cdot 66-15 \cdot 65) \\
7 \cdot 60(1 \cdot 22-47 \cdot 43) \\
4 \cdot 69(2 \cdot 18-11 \cdot 32)\end{array}$ \\
\hline $\begin{array}{l}\text { Smoking state: } \\
\text { Never } \\
\text { Ex }>10 y \\
\text { Ex } 6-10 y \\
\text { Ex }<6 \text { y } \\
\text { Current }<20 / \text { day } \\
\text { Current } \geqslant 20 / \text { day }\end{array}$ & $\begin{array}{l}1.0 \\
0.99(0.44-2.23) \\
0.95(0.34-2.67) \\
2.30(0.80-6.65) \\
0.72(0.30-1.76) \\
1.07(0.49-2.34)\end{array}$ \\
\hline
\end{tabular}

consistent effect ( $p=0.57)$ on the relative risk of asbestosis. The effects of the smoking variables were almost the same even without the adjustment for exposure to asbestos included in table 5, indicating little confounding between the two exposures.

\section{Discussion}

This study has shown that smoking state is related to the rate of lung cancer in Wittenoom crocidolite workers. The risk in current smokers was dose related and the risk in ex-smokers was greatest in the period up to six years from stopping. There was a smaller but still highly significant effect of crocidolite exposure on the rate of lung cancer. In our study this was best expressed in terms of the logarithm of total cumulative exposure rather than with separate terms for duration and intensity as was found previously. ${ }^{3}$

Statistical modelling of the effect of smoking and exposure to crocidolite on the risk of lung cancer indicated that these effects acted multiplicatively as reported in cohorts exposed to other forms of asbestos.

Previous studies have found a reduction in relative risk from asbestos associated lung cancer long after exposure has ceased. ${ }^{36}{ }^{37}$ That this should be so is supported by theoretical principles of the multistage theory of carcinogenesis if it is assumed that asbestos acts at a late stage in the disease process and there is elimination of asbestos from the lungs. ${ }^{6}$ Because of the way the cohort for this study was defined long after exposure had ceased, any such effect would, however, probably be overemphasised because of survivor effects analogous to the healthy worker effect.

The high relative risks in ex-smokers could be due 
to inaccuracies in self reporting or, more likely, to people quitting after either experiencing symptoms or being advised to stop smoking after reporting symptoms. The higher risk for asbestosis among recent quitters supports this interpretation.

Both duration and intensity of exposure to crocidolite as well as cumulative exposure have been shown to be strongly related to the risk of asbestosis. The better fit of the quadratic model and the use of cumulative exposure has also been shown before ${ }^{1322}$ and has some theoretical support from consideration of lung clearance mechanisms. ${ }^{13}$

Other studies have shown that increasing age and smoking have an effect on producing minor grades of abnormality on the chest $x$ ray films even in the absence of exposure to asbestos. ${ }^{23839}$ Hence it may not be that smoking is making any difference to the process of asbestosis as has been assumed in the analysis. The radiological abnormalities related to smoking that mimic pneumoconiosis probably result from peribronchiolar fibrosis rather than diffuse interstitial fibrosis. If this is true, a small additive effect of smoking on radiographic abnormalities might be anticipated. Where it is possible to judge, other studies have shown such an additive effect, ${ }^{1020}$ although neither study was able to adjust for level of exposure to asbestos ${ }^{39}$ as has been done here. A specific measure of the severity of diffuse interstitial fibrosis would be needed to show with any certainty an effect of smoking on asbestosis.

The strong effect of site of work on incidence of asbestosis has been noted before ${ }^{3}$ and is likely to be caused by the greater awareness of asbestosis and claims procedures among miners than among millers and also the possible prejudices of members of the Pneumoconiosis Board in regarding exposure outside the mine and mill as not being heavy.

One problem with this study is that only the smoking history obtained in 1979 was used for analysis and this did not allow for change in smoking habits thereafter. Given the comparatively short follow up this is unlikely to be a major problem. Loss to follow up was a serious problem in other studies of the Wittenoom cohort where the whole cohort of workers was included ${ }^{2} 3$ but for the cohort studied here, restricted to those traced and responding, no subject was lost to the end of 1986 . It is unikely that the differences between responders and non-responders in the 1979 survey would include differences in their reaction to smoking or to exposure to asbestos.

This study has shown that the effect of crocidolite on the incidence of lung cancer multiplies that of smoking, a finding that is consistent with previous studies of exposure to other forms of asbestos. In the Wittenoom cohort the diagnosis of asbestosis for compensation purposes or as the cause of death is closely related to the degree of exposure to crocidolite but not to smoking habits.
Requests for reprints to: Nicholas de Klerk, $\mathrm{NH}$ and MRC Unit of Epidemiology and Preventive Medicine, Department of Medicine, University of Western Australia, Nedlands, Western Australia, 6009.

1 Armstrong BK, de Klerk NH, Musk AW, Hobbs MST. Mortality in miners and millers of crocidolite in Western Australia. Br J Ind Med 1988;45:5-13.

2 de Klerk NH, Armstrong BK, Musk AW, Hobbs MST. Cancer mortality in relation to measures of occupational exposure to crocidolite at Wittenoom Gorge in Western Australia. Br J Ind Med 1989;46:529-36.

3 de Klerk NH, Armstrong BK, Musk AW, Hobbs MST. Predictions of future asbestos-related disease cases among former miners and millers of crocidolite in Western Australia. Med J Aust 1989;151:616-20.

4 Berry G, Newhouse ML, Antonis P. Combined effect of asbestos and smoking on mortality from lung cancer and mesothelioma in factory workers. $\mathrm{Br} \mathrm{J}$ Ind Med 1985;42:12-18.

5 Saracci $R$. The interactions of tobacco smoking and other agents in cancer etiology. Epidemiol Rev 1987;9:175-93.

6 Day NE, Brown CC. Multistage models and primary prevention of cancer. J Natl Cancer Inst 1980;64:977-89.

7 Baker JE. Lung cancer incidence amongst previous employees of an asbestos mine in relationship to crocidolite exposure and tobacco smoking. Perth: University of Western Australia, 1985. (PhD thesis.)

8 Doll R, Peto J. Asbestos. Effects on health of exposure to asbestos. London: HMSO, 1985.

9 Anderson HA, Lilis R, Daum SM, Selikoff IJ. Asbestosis among household contacts of asbestos factory workers. Ann NY Acad Sci 1979;330:386-99.

10 Kilburn KH, Warshaw R, Thornston JC. Asbestos disease and family contacts of shipyard workers. Am J Public Health 1985;75:615-17.

11 Finkelstein MM, Vingilis JJ. Radiographic abnormalities among asbestos-cement workers. Am Rev Respir Dis 1984;129:17-22.

12 Irwig LM, duToit RSJ, Sluis-Cremer GK, et al. Risk of asbestosis in crocidolite and amosite mines in South Africa. Ann NY Acad Sci 1979;330:35-52.

13 Berry G, Gilson JC, Holmes S, Lewinsohn H, Roach S. Asbestosis: a study of dose response relationships in an asbestos textile factory. $\mathrm{Br} J$ Ind $\mathrm{Med}$ 1979;36:98-112.

14 Copes R, Thomas D, Becklake MR. Temporal patterns of exposure and nonmalignant pulmonary abnormality in Quebec chrysotile workers. Arch Environ Health 1985;40: 80-7.

15 Liddell FDK, Gibbs GW, McDonald JC. Radiological changes and fibre exposure in chrysotile workers aged $60-69$ years at Thetford mines. Ann Occup Hyg 1982;26:889-98.

16 Weiss W. Cigarette smoke, asbestosis, and small irregular opacities. Am Rev Respir Dis 1984;130:293-301.

17 Kilburn KH, Lilis R, Anderson HA, Miller A, Warshaw RH. Interaction of asbestos, age and cigarette smoking in producing radiographic evidence of diffuse pulmonary fibrosis. $\mathrm{Am}$ J Med 1986;80:377-81.

18 Armstrong BG, McDonald JC, Sebastien P, Althouse R, Amandus HE, Wheeler $R$. Radiological changes in vermiculite workers exposed to tremolite. Ann Occup Hyg 1988;32 (suppl 1):469-74.

19 Murdoch RM, Miller BG, Jacobsen M. Possible effects of the introduction of the 1969 asbestos regulations. Ann Occup Hyg 1988;32:505-12.

20 Ducatman AM, Withers BF, Yang WN. Smoking and roentgenographic opacities in US Navy asbestos workers. Chest 1990;97:810-13.

21 Viallat JR, Boutin C, Pietri JF, Fondarai J. Late progression of radiographic changes in Canari chrysotile mine and mill exworkers. Arch Environ Health 1983;38:54-8.

22 Finkelstein MM. A study of dose-response relationships for asbestos associated disease. $\mathrm{Br} J$ Ind Med 1985;42:319-25.

23 Cookson WOC, de Klerk NH, Musk AW, Armstrong BK, Glancy JJ, Hobbs MST. Prevalence of radiographic asbestosis in crocidolite miners and millers at Wittenoom, Western Australia. Br J Ind Med 1986;43:450-7.

24 Cookson WOC, Musk AW, Glancy JJ, et al. Compensation, radiographic changes, and survival in applicants for asbestosis compensation. Br J Ind Med 1985;42:461-8.

25 Cookson WOC, de Klerk NH, Musk AW, Glancy JJ, Armstrong 
BK, Hobbs MST. The natural history of asbestosis in former crocidolite workers of Wittenoom Gorge. Am Rev Respir Dis 1986;133:994-8.

26 Major G. Asbestos dust exposure. In: Major G, ed. Proceedings of the first Australian pneumoconiosis conference, Sydney, 1968. Sydney: Joint Coal Board, 1968:467-74.

27 Breslow NE, Lubin JH, Marek P, Langholz B. Multiplicative models and cohort analysis. Journal of the American Statistical Association 1983;78:1-12.

28 Statistics and Epidemiology Research Corporation Program EGRET. Seattle, Washington: 1987.

29 Selikoff IJ, Hammond EC, Seidman H. Mortality experience of insulation workers in the United States and Canada, 19431976. Ann NY Acad Sci 1979;330:91-116.

30 Peto J, Doll R, Hermon C, Binns W, Clayton R, Goffe T Relationship of mortality to measures of environmental asbestos pollution in an asbestos textile factory. Ann Occup Hyg 1985;29:305-55,

31 McDonald AD, Fry JS, Woolley AJ, McDonald JC. Dust exposure and mortality in an American chrysotile textile factory. Br J Ind Med 1983;40:361-7.

32 World Health Organisation. Asbestos and other natural mineral fibres. Geneva: WHO, 1986. (Environmental health criteria 53).
33 Peto J. Some problems in dose-response estimation in cancer epidemiology. In: Vouk VB, Butler GC, Hoel DG, Peakall DB eds. Methods for estimating risk of chemical injury: human and non-human biota and ecosystems. New York: Wiley and Sons, 1985.

34 Doll R, Peto R. Cigarette smoking and bronchial carcinoma. $J$ Epidemiol Community Health 1978;32:303-13.

35 McCullagh P, Nelder JA. Generalised Linear Models. London: Chapman and Hall, 1983.

36 Nicholson WJ, Perkel G, Selikoff IJ, Seidman H. Cancer from occupational asbestos exposure projections 1980-2000. In: Peto $R$ and Schneiderman $M$ eds. Quantification of occupational cancer. Cold Spring Harbour Laboratory: Banbury Reports 1981;9:87-111.

37 Walker AM. Declining relative risks for lung cancer after cessation of asbestos exposure. J Occup Med 1984;26:421-6.

38 Weiss W. Smoking and pulmonary fibrosis. J Occup Med 1988;30:33-9.

39 Weiss W. The cigarette factor in asbestosis. Chest 1990;97: 769-70.

Accepted 19 November 1990

\section{Vancouver style}

All manuscripts submitted to the $B r J$ Ind Med should conform to the uniform requirements for manuscripts submitted to biomedical journals (known as the Vancouver style).

The Br J Ind Med, together with many other international biomedical journals, has agreed to accept articles prepared in accordance with the Vancouver style. The style (described in full in $\mathrm{Br}$ Med J, 24 February 1979, p 532) is intended to standardise requirements for authors.

References should be numbered consecutively in the order in which they are first mentioned in the text by Arabic numerals above the line on each occasion the reference is cited (Manson ${ }^{1}$ confirmed other reports ${ }^{2-5} \ldots$... In future references to papers submitted to the $B r J$ Ind Med should include: the names of all authors if there are six or less or, if there are more, the first three followed by et al; the title of journal articles or book chapters; the titles of journals abbreviated according to the style of Index Medicus; and the first and final page numbers of the article or chapter.

Examples of common forms of references are:

1 International Steering Committee of Medical Editors. Uniform requirements for manuscripts submitted to biomedical journals. Br Med J 1979;1:532-5.

2 Soter NA, Wasserman SI, Austen KF. Cold urticaria: release into the circulation of histamine and eosino-phil chemotactic factor of anaphylaxis during cold challenge. N Engl J Med 1976;294:687-90.

3 Weinstein L, Swartz MN. Pathogenic properties of invading micro-organisms. In: Sodeman WA Jr, Sodeman WA, eds. Pathologic physiology: mechanisms of disease. Philadelphia: W B Saunders, 1974:457-72. 